\title{
INTERFERÊNCIA DE Raphanus sativus NA PRODUTIVIDADE DE Cultivares DE SoJA ${ }^{1}$
}

\author{
Interference of Raphanus sativus in Soybean Cultivars' Yield
}

BIANCHI, M.A. ${ }^{2}$, FLECK, N.G. ${ }^{3}$, AGOSTINETTO, D. ${ }^{4}$ e RIZZARDI, M.A. ${ }^{5}$

\begin{abstract}
RESUMO - A forte dependência de herbicidas para o controle de plantas daninhas em soja tem como consequência a seleção de espécies daninhas tolerantes e resistentes. $\mathrm{O}$ manejo integrado considera, além do uso de herbicidas, técnicas como a habilidade competitiva do cultivar para controlar plantas daninhas. Com os objetivos de avaliar a resposta de cultivares à competição com nabo (Raphanus sativus) e identificar aqueles portadores de habilidade competitiva superior, foi conduzido experimento em campo, em Cruz Alta-RS, na safra 2000/01. Testaram-se duas condições de competição (ausência ou presença de nabo forrageiro durante a fase de desenvolvimento vegetativo da soja), combinadas com 11 cultivares da cultura. O efeito da competição com nabo é variável entre os cultivares, caracterizando variabilidade genética que permite selecionar genótipos portadores de habilidade competitiva superior. A competição com nabo reduz a estatura de planta, o comprimento médio dos ramos e a produtividade de grãos de soja. Entre os genótipos de soja utilizados, o cultivar MSoy 6101 destaca-se quanto à habilidade competitiva pela maior produtividade potencial de grãos na ausência de competição e pela capacidade de mantê-la diante da competição com nabo.
\end{abstract}

Palavras-chave: Glycine max, competitividade, planta daninha, nabo.

\begin{abstract}
The strong dependence on herbicides for weed control in soybean has led to the selection of tolerant and/or resistant weed plants. Besides the use of herbicides, integrated management includes techniques such as cultivar competitive ability to control weed plants. This work aimed to evaluate cultivar response to competition with forage turnip (Raphanus sativus) and to identify carriers of superior competitive ability. The experiment was carried out under field conditions in Cruz Alta-RS, during the 2000/01 season. Two competition conditions (absence and presence of forage turnip during the soybean vegetative growth stage) were tested in combination with 11 soybean cultivars. The effect of forage turnip competition varies among cultivars, characterizing genetic variability, which permits the selection of genotypes with higher competitive ability. Forage turnip competition reduces plant height, twig average length and soybean grain yield. Among the soybean genotypes used, the cultivar M Soy 6101 shows outstanding competitive ability due to its higher grain yield potential, both with and without forage turnip competition.
\end{abstract}

Keywords: Glycine max, competitivity, weed, forage turnip.

\section{INTRODUÇÃO}

O cultivo de soja no Brasil depende fortemente do uso de herbicidas para o controle de plantas daninhas. O uso quase que exclusivo do controle químico de plantas daninhas torna o manejo mais simples. No entanto, a dependência de herbicidas gera ambiente favorável ao surgimento de plantas daninhas resistentes, mudança da flora daninha e movimento

1 Recebido para publicação em 24.3.2010 e aprovado em 17.2.2011.

Parte da tese do primeiro autor para obtenção do título de Doutor em Fitotecnia, pelo PPG Fitotecnia, Faculdade de Agronomia, Universidade Federal do Rio Grande do Sul-UFRGS.

2 Pesquisador da CCGL Tecnologia e Professor da Universidade de Cruz Alta, Caixa Postal 10, $98100-970$ Cruz Alta-RS, <mariobianchi@fundacep.com.br>; ${ }^{3}$ Professor Aposentado da Universidade Federal do Rio Grande do Sul; ${ }^{4}$ Professor do Dep. de Fitossanidade, Faculdade de Agronomia Eliseu Maciel, Universidade Federal de Pelotas; ${ }^{5}$ Professor da Faculdade de Agronomia e Medicina Veterinária, Universidade de Passo Fundo. 
de herbicidas para locais não alvos (Buhler, 2002). Estudos sobre competitividade de culturas com plantas daninhas permitem desenvolver estratégias para sua inserção em sistemas de manejo integrado.

Identificar características de planta que confiram maior habilidade competitiva (HC) com plantas daninhas tem sido alvo de pesquisas em várias culturas, inclusive em soja (Jannink et al., 2000, 2001; Lemerle et al., 2001a). A HC caracteriza-se pela dominância de um indivíduo sobre seus vizinhos, os quais utilizam, simultaneamente, um mesmo recurso com limitada disponibilidade (Aarssen, 1983). Quanto aos efeitos, pode ser analisada sob dois aspectos: supressão do crescimento de vizinhos e tolerância à presença de vizinhos (Goldberg \& Landa, 1991). Em sistemas de produção agrícola, o efeito supressivo deve preponderar em relação à tolerância das culturas, por reduzir a matéria seca e a produção de sementes das plantas daninhas e beneficiar seu manejo nas culturas subsequentes (Jordan, 1993). Mesmo que a cultura mantenha ou altere pouco seu crescimento e sua produtividade sob competição (tolerância), não exercerá alteração expressiva no crescimento das plantas daninhas, beneficiando pouco o manejo dessas espécies durante o ciclo de crescimento da cultura e em cultivos subsequentes.

Geralmente, maior tamanho de planta exprime maior competitividade. Nesse sentido, a matéria seca frequentemente é indicadora de maior $\mathrm{HC}$; contudo, quando ocorre pequena variação na matéria seca de plantas, a estatura, ou outra variável, pode determinar melhor a dominância de uma espécie sobre outra (Gaudet \& Keddy, 1988). Estatura e indice de área foliar (IAF) elevados e rápida formação do dossel determinam, com grande frequência, culturas com HC superior (Callaway, 1992; Drews et al., 2009). Entretanto, diferenças na HC entre cultivares podem não se relacionar com características morfológicas que afetam a interceptação de luz, e sim serem específicas do cultivar e não genéricas (Paynter \& Hills, 2009).

Plantas de soja portadoras de estatura elevada (Shilling et al.,1995) identificam elevado potencial competitivo com plantas daninhas. Na fase inicial de crescimento, a estatura de planta de soja apresenta alta herdabilidade e correlação genética com supressão de plantas daninhas, constituindo-se em critério ideal para seleção de plantas mais competitivas (Jannink et al., 2001).

A relação entre duração do ciclo de crescimento em cultivares de soja e HC ainda é controversa. Em alguns ambientes, os cultivares tardios mostram-se mais competitivos (Monks \& Oliver, 1988; Shilling et al., 1995; Nordby et al., 2007); em outros, são os precoces (Bennett \& Shaw, 2000; Jannink et al., 2000); enquanto outros não demonstram existir relação entre ciclo e HC (James et al.,1988). Parte dessa divergência deve-se à utilização de espécies cultivadas de ciclo tardio competindo com espécies daninhas de ciclo precoce, ou vice-versa. Geralmente, plantas de ciclo longo possuem crescimento inicial lento; assim, cultivar tardio tende a ser competidor fraco diante de espécie daninha de ciclo precoce. Já o rápido crescimento de cultivar de soja precoce suprime plantas daninhas de ciclo longo e, pelo fato de a colheita da cultura ocorrer antes da maturação daquelas, há redução na produção de sementes das infestantes (Bennett \& Shaw, 2000).

A importância da duração do ciclo de crescimento na competitividade das culturas reside no padrão de crescimento imposto na fase inicial de desenvolvimento. Cultivares precoces possuem crescimento inicial mais vigoroso que o dos tardios (Jannink et al., 2000). Esse padrão de crescimento confere àqueles maior capacidade competitiva no período inicial. Por sua vez, cultivares tardios crescem mais lentamente na fase inicial, porém mantêm seu crescimento por maior período de tempo, tornando-se fortes competidores em estádios mais avançados de desenvolvimento (Jannink et al., 2000). Mesmo que possuam crescimento mais lento, cultivares tardios resistem melhor à competição nas fases iniciais de crescimento, demonstrando ser mais flexíveis quanto ao momento de controle, o qual pode ser realizado mais tardiamente sem resultar em prejuízo da produtividade (Nordby et al., 2007). A relação inversa de crescimento inicial entre cultivar precoce e tardio faz com que exista certa associação da HC com a duração do ciclo de crescimento. 
A maturação das espécies daninhas predominantes em lavouras de soja no Sul do Brasil ocorre, na maioria dos casos, antes da colheita dos cultivares precoces de soja (Voll et al., 2002). Desse modo, o crescimento inicial mais vigoroso de cultivares precoces pode ser decisivo na resposta de sua competitividade com a flora daninha predominante. Por outro lado, é viável selecionar cultivar tardio que apresente rápido incremento em estatura na fase inicial de desenvolvimento, sem prejudicar seu crescimento nos estádios mais avançados, conferindo-lhe, assim, alta competitividade durante todo o ciclo de crescimento (Jannink et al., 2001).

Os primeiros trabalhos que analisaram a competitividade de culturas estabeleceram relação inversa entre $\mathrm{HC}$ e produtividade (Jennings \& Aquino, 1968). Nesses trabalhos, plantas mais competitivas produziam mais matéria seca em detrimento da produção de grãos. Estudos recentes, porém, indicam que cultivares competitivos também podem originar alta produtividade (Lemerle et al., 2001b; Haefele et al., 2004). Em soja, foi demonstrado que é possivel romper a relação inversa que ocorre entre cultivares precoces e tardios para crescimento inicial (Jannink et al., 2001), sugerindo que a possível associação negativa entre $\mathrm{HC}$ e produtividade pode ser superada pelo melhoramento genético. Objetivou-se com este experimento avaliar a resposta de cultivares de soja à competição com nabo (Raphanus sativus) e identificar aqueles portadores de HC superior.

\section{MATERIAL E MÉTODOS}

Conduziu-se um experimento em campo durante o ano agrícola 2000/01, em Cruz AltaRS, na Fundação Centro de Experimentação e Pesquisa (FUNDACEP). O solo da área experimental apresenta as seguintes características físico-químicas: argila $=63 \%$; matéria orgânica $=3 \%$; $\mathrm{pH}$ em água $=5,4 ; \mathrm{P}=19 \mathrm{mg} \mathrm{L}^{-1}$; e K $=140 \mathrm{mg} \mathrm{L}^{-1}$. Neste estudo, um experimento fatorial $2 \times 11$, testaram-se duas condições de competição (ausência e presença de competidor) combinadas com 11 cultivares de soja [BR 16, Bragg, BRS 154, CD 201, CEPS 9678, CEPS 9703, Fepagro RS 10 (RS 10), FT 2000, Fundacep 38, IAS 5 e MSoy 6101]. Os tratamentos resultantes dessas combinações foram dispostos no delineamento em parcelas subdivididas, com as parcelas distribuídas em quatro blocos.

Foi escolhido como competidor o Raphanus sativus (nabo ou nabo forrageiro), por representar espécie daninha da cultura de soja e por mostrar germinação e emergência mais uniformes do que espécies daninhas típicas. Emergência uniforme garante densidade de plantas semelhante entre as unidades experimentais; resultando em pressão de competição uniforme e, consequentemente, maior confiabilidade dos resultados.

A área experimental, manejada no sistema de semeadura direta, foi semeada no dia 17 de novembro de 2000, sendo as sementes de nabo (55 sementes aptas $\mathrm{m}^{-2}$ ) distribuídas em linhas espaçadas de 0,17 m, e as de soja (33 sementes aptas $\mathrm{m}^{-2}$ ), em linhas espaçadas de $0,5 \mathrm{~m}$. A semeadura do nabo precedeu a da soja, o qual foi semeado em sentido perpendicular ao das linhas de soja. As práticas culturais adotadas seguiram as recomendações técnicas preconizadas para a cultura. O controle de plantas daninhas gramíneas foi feito com o herbicida clethodim (96 $\left.\mathrm{g} \mathrm{ha}^{-1}\right)$, e o das dicotiledôneas, exceto nabo, foi realizado por meio de arranque manual.

$\mathrm{Na}$ soja, foram efetuadas avaliações durante o ciclo vegetativo de crescimento (Fleck et al., 2006) e na época da maturação. As características de planta determinadas foram: estatura, número de ramos (NR), comprimento médio de ramos (CMR) e produtividade de grãos.

No estádio fenológico $R_{8}(95 \%$ dos legumes apresentando a cor do legume maduro), coletaram-se, aleatoriamente, na respectiva área útil, 10 plantas para determinar estatura, número e comprimento de ramos, matéria seca da parte aérea (MPA) e matéria seca dos grãos (corrigida para $13 \%$ de umidade). A estatura de planta foi determinada medindose a distância da base até o ponto de crescimento na extremidade do caule. Considerouse como ramo a estrutura originada no nó do caule, cuja diferenciação da primeira folha era visivel a olho nu (estrutura com aproximadamente $1 \mathrm{~cm}$ de comprimento). O comprimento de cada ramo foi mensurado, sendo o CMR o resultado da divisão do comprimento 
total dos ramos pelo número de ramos das plantas.

O final do ciclo de crescimento da soja correspondeu ao estádio em que a maior parte das plantas encontrava-se na fase de maturação de colheita, identificado através de inspeção das unidades experimentais a cada dois dias. As plantas de soja contidas na área útil foram colhidas manualmente. Após trilha das plantas, procedeu-se à limpeza dos grãos e correção da umidade para $13 \%$. A produtividade representou a massa da matéria seca dos grãos resultantes da trilha acrescida daquela obtida nas 10 plantas coletadas no estádio $R_{8}$, expressando-se os resultados em kg ha ${ }^{-1}$.

Determinou-se a produtividade biológica aparente $\left(\mathrm{PB}_{\mathrm{a}}\right)$ e $\mathrm{o}$ indice de colheita aparente $\left(\mathrm{IC}_{\mathrm{a}}\right)$. A $\mathrm{PB}_{\mathrm{a}}$ representou a soma da MPA acrescida da massa da matéria seca de grãos em $R_{8}$, sendo expressa em g por planta. $\mathrm{O} \mathrm{IC}_{a}$ originou-se da razão entre a matéria seca de grãos obtida em $\mathrm{R}_{8}$ e a $\mathrm{PB}_{a}$, sendo expresso em porcentagem.

Quando o teste $\mathrm{F}$ da análise de variância indicou significância (efeito principal $p \leq 0,05$; interação $\mathrm{p} \leq 0,15)$, as médias foram comparadas pelo teste de Tukey $(\mathrm{p}<0,05)$. Para interação significativa, calculou-se a redução causada pela competição com nabo durante a fase vegetativa da cultura, da seguinte forma: Redução na variável = valor médio da variável na ausência da competição (média das quatro repetições) - valor da variável em cada repetição na presença de competição. Esses resultados foram analisados como experimento em blocos ao acaso com quatro repetições, sendo as médias comparadas pelo teste de Tukey $(\mathrm{p}<0,05)$.

\section{RESULTADOS E DISCUSSÃO}

A população de plantas de nabo foi uniforme nas unidades experimentais, variando de 42 a 50 plantas $\mathrm{m}^{-2}$, condição importante para garantir a avaliação consistente de competitividade dos cultivares de soja. O nabo cresceu juntamente com os cultivares de soja até 60 dias após a emergência da cultura (DAE). Após esse período o efeito de competidores foi desprezivel, devido à colheita do nabo e à presença insignificante de outras espécies daninhas.

A presença do nabo até $60 \mathrm{DAE}$ (equivalente ao início do florescimento da maioria dos cultivares de soja) exerceu efeito negativo sobre a estatura de planta na maturação da soja (Tabela 1). A competição de nabo reduziu em 12 a $25 \%$ a estatura de planta, sendo os cultivares CD 201 e BRS 154 aqueles que sofreram maior redução, e IAS 5, Fepagro RS 10, CEPS 9703 e CEPS 9678, aqueles em que a competição exerceu menor efeito sobre a estatura. Os cultivares FT 2000 e MSoy 6101 apresentaram as maiores estaturas de planta, tanto na ausência como na presença de nabo. Também, independentemente da condição de competição, os cultivares mais baixos foram IAS 5 e Bragg. Devido ao tipo de crescimento indeterminado, os cultivares FT 2000 e MSoy 6101 continuam o crescimento em estatura até a maturação, enquanto os cultivares com tipo de crescimento determinado reduzem substancialmente o incremento em estatura tão logo se inicia o florescimento. A característica de manter o crescimento em estatura durante todo o ciclo de desenvolvimento garante maior competitividade aos cultivares de soja (Jannink et al., 2001).

É de se supor que a maior parte do prejuízo causado pelo nabo não se deveu à disputa pela radiação solar fotossinteticamente ativa incidente no dossel da soja. Em geral, plantas que competem por luz tendem a crescer mais em estatura para obter vantagem na captação desse recurso do ambiente (Rajcan \& Swanton, 2001), resultado da baixa qualidade de luz predominante na parte inferior do dossel (Crotser et al., 2003). Parte do presente trabalho analisou a interferência do nabo na fase vegetativa e indicou que no primeiro mês de crescimento da soja a estatura de planta não foi afetada pela presença de nabo (Fleck et al., 2006). Como houve redução em estatura na maturação da cultura decorrente da presença do nabo na fase vegetativa, é possivel que recursos do solo estivessem envolvidos na competição inicial.

O nabo caracterizou-se por curto ciclo de crescimento durante a estação estival (60 dias), o que implica ter suprida toda a sua demanda por recursos do solo durante esse 
período, restando menor quantidade para atender às demandas das plantas de soja. A soja manifestou esse efeito de competição reduzindo o crescimento em estatura (Tabela 1). Isso indica que os recursos do solo estiveram envolvidos na competição soja-nabo. Descarta-se, por outro lado, um possivel efeito alelopático do nabo sobre a soja, porque, quando em associação com plantas de soja, o nabo não imprimiu redução em MPA da soja (Bianchi et al., 2006).

A presença do nabo até 60 DAE não afetou o NR, havendo diferenças apenas entre os cultivares (Tabela 2). Os cultivares Bragg, CEPS 9678 e Fundacep 38 destacaram-se como portadores do maior NR na maturação, $\mathrm{e}$ FT 2000 e MSoy 6101 apresentaram menor NR. Os cultivares Bragg e FT 2000 posicionaram-se como de maior e de menor NR, respectivamente.

A presença do nabo até $60 \mathrm{DAE}$ exerceu efeito negativo no CMR de alguns cultivares (Tabela 2). A presença de nabo reduziu substancialmente o CMR dos cultivares Bragg, BRS 154 e CEPS 9678 na maturação. Contudo, quando se calculou a redução do CMR, o cultivar Bragg apresentou a maior redução no
CMR (33\%), e os cultivares Fepagro RS 10, CEPS 9703 e FT 2000, a menor redução no CMR (0 a 4\%), indicando a menor sensibilidade destes genótipos à competição quando analisado o crescimento dos ramos. O maior CMR ocorreu em MSoy 6101 na ausência de competição e em MSOY 6101 e em FT 2000 quando submetidos à competição de nabo. Em oposição ao verificado no período vegetativo (Fleck et al., 2006), na maturação da soja o NR associou-se negativamente com o CMR $(r=-0,32 ; p<0,01)$, caracterizando relação de compensação na planta.

A produtividade biológica aparente $\left(\mathrm{PB}_{\mathrm{a}}\right)$ dos cultivares de soja diminuiu quando eles estiveram associados ao nabo até $60 \mathrm{DAE}$; o contrário ocorreu com o índice de colheita aparente ( $\mathrm{IC}_{\mathrm{a}}$ ), o qual aumentou na presença do nabo (Tabela 3). O cultivar CEPS 9678 destacou-se dos demais, apresentando os maiores $\mathrm{PB}_{\mathrm{a}}$ e $\mathrm{IC}_{\mathrm{a}}$. O cultivar IAS 5 deteve a menor $\mathrm{PB}_{\mathrm{a},}$ e os cultivares Bragg, CEPS 9703 e FT 2000, os menores valores de $\mathrm{IC}_{\mathrm{a}}$. $\mathrm{A} \mathrm{PB}_{\mathrm{a}}$ associou-se positivamente com o IC $\mathrm{I}_{\mathrm{a}} \mathrm{r}=0,51$; $\mathrm{p}<0,0001$ ), reforçando o fato de que plantas que produzem mais matéria seca conseguem direcionar maior quantidade de fotoassimilados para a produção de grãos.

Tabela 1 - Estatura de plantas (cm) de cultivares de soja na maturação, sob duas condições de competição com nabo. Fundacep, Cruz Alta-RS, 2000/01

\begin{tabular}{|c|c|c|c|c|}
\hline \multirow{2}{*}{ Cultivar } & \multirow{2}{*}{$\begin{array}{l}\text { Ausência de } \\
\text { competição }\end{array}$} & \multirow{2}{*}{$\begin{array}{l}\text { Presença de } \\
\text { competição }\end{array}$} & \multicolumn{2}{|c|}{ Redução de estatura (RE) } \\
\hline & & & $\mathrm{RE}(\mathrm{cm})^{{ }^{1 /}}$ & $\operatorname{RE}(\%)^{2 /}$ \\
\hline IAS 5 & A $84 \mathrm{e}^{\frac{3 /}{}}$ & B $70 \mathrm{f}$ & $14 \mathrm{~b}$ & 17 \\
\hline BR 16 & A $101 \mathrm{bc}$ & B $83 \mathrm{~cd}$ & $18 \mathrm{ab}$ & 18 \\
\hline CD 201 & A 104 b & B 80 de & $24 \mathrm{a}$ & 23 \\
\hline MSoy 6101 & A $131 \mathrm{a}$ & B $116 \mathrm{a}$ & $15 \mathrm{ab}$ & 11 \\
\hline Bragg & A 90 de & B 73 ef & $18 \mathrm{ab}$ & 20 \\
\hline BRS 154 & A $103 \mathrm{~b}$ & B 79 def & $25 \mathrm{a}$ & 24 \\
\hline Fundacep 38 & A $100 \mathrm{bc}$ & B $81 \mathrm{de}$ & $19 \mathrm{ab}$ & 19 \\
\hline Fepagro RS 10 & A 104 b & B $92 \mathrm{bc}$ & $12 \mathrm{~b}$ & 12 \\
\hline CEPS 9703 & A 109 b & B $97 \mathrm{~b}$ & $13 \mathrm{~b}$ & 12 \\
\hline FT 2000 & A 137 a & B 119 a & $19 \mathrm{ab}$ & 14 \\
\hline CEPS 9678 & A $94 \mathrm{~cd}$ & B 82 de & $12 \mathrm{~b}$ & 13 \\
\hline CV (\%) Competição & \multicolumn{2}{|c|}{5,1} & & \\
\hline CV $(\%)$ Cultivares & \multicolumn{2}{|c|}{4,0} & \multicolumn{2}{|c|}{24,5} \\
\hline
\end{tabular}

1/ $\mathrm{RE}(\mathrm{cm})=$ estatura média do cultivar na ausência de competição - estatura do cultivar na presença de competição; $\underline{2}^{\prime} \mathrm{RE}(\%)=$ $\left(\mathrm{RE}(\mathrm{cm}) /\right.$ estatura média do cultivar na ausência de competição) x $100 ;{ }^{3 /}$ Médias antecedidas pela mesma letra maiúscula nas linhas, entre condições de competição, ou seguidas pela mesma letra minúscula nas colunas, entre cultivares, não diferem pelo teste de Tukey a $5 \%$ de probabilidade. 
Tabela 2 - Número de ramos (NR) e comprimento médio de ramos (CMR) em plantas de cultivares de soja na maturação, sob duas condições de competição com nabo. Fundacep, Cruz Alta-RS, 2000/01

\begin{tabular}{|c|c|c|c|c|c|}
\hline \multirow{2}{*}{$\frac{\text { Fator/tratamento }}{\text { Cultivar }}$} & \multirow{2}{*}{$\begin{array}{c}\text { NR } \\
\text { (ramos por planta) }\end{array}$} & \multicolumn{2}{|c|}{$\begin{array}{c}\text { CMR } \\
\text { (cm por ramo) }\end{array}$} & \multicolumn{2}{|c|}{$\mathrm{R}_{\mathrm{CMR}^{1}}{ }^{1 /}$} \\
\hline & & $\begin{array}{l}\text { Ausência de } \\
\text { competição }\end{array}$ & $\begin{array}{l}\text { Presença de } \\
\text { competição }\end{array}$ & (cm por ramo) & $(\%)$ \\
\hline IAS 5 & $4,8 \mathrm{~cd}^{2 /}$ & A 33,5 bc & A $27,5 \mathrm{~cd}$ & $5,9 \mathrm{abc}$ & 18 \\
\hline BR 16 & $5,1 \mathrm{~cd}$ & A 35,1 bc & A $29,2 \mathrm{bcd}$ & $5,8 \mathrm{abc}$ & 16 \\
\hline CD 201 & $4,8 \mathrm{~cd}$ & A $42,9 \mathrm{~b}$ & A 36,7 bc & $6,1 \mathrm{abc}$ & 14 \\
\hline MSoy 6101 & $4,1 \mathrm{de}$ & A 56,5 a & A $55,4 \mathrm{a}$ & $3,5 \mathrm{bc}$ & 6 \\
\hline Bragg & $7,0 \mathrm{a}$ & A 37,4 bc & B $25,2 \mathrm{~d}$ & $12,2 \mathrm{a}$ & 33 \\
\hline BRS 154 & $5,9 \mathrm{abc}$ & A $42,6 \mathrm{~b}$ & B $32,5 \mathrm{bcd}$ & $10,0 \mathrm{ab}$ & 23 \\
\hline Fundacep 38 & $6,4 \mathrm{ab}$ & A $32,0 \mathrm{bc}$ & A $32,4 \mathrm{bcd}$ & $4,7 \mathrm{bc}$ & 15 \\
\hline Fepagro RS 10 & $5,9 \mathrm{abc}$ & A $28,5 \mathrm{c}$ & A $31,6 \mathrm{bcd}$ & $0,5 \mathrm{c}$ & 2 \\
\hline CEPS 9703 & $5,5 \mathrm{bc}$ & A 39,1 bc & A 39,6 b & $1,4 \mathrm{c}$ & 4 \\
\hline FT 2000 & $3,4 \mathrm{e}$ & B $41,6 \mathrm{~b}$ & A 52,9 a & $0,0 \mathrm{c}$ & 0 \\
\hline CEPS 9678 & $6,5 \mathrm{ab}$ & A $41,6 \mathrm{~b}$ & B $32,2 \mathrm{bcd}$ & $9,3 \mathrm{ab}$ & 22 \\
\hline CV $(\%)$ & 14,6 & 13,0 & & 52,8 & \\
\hline \multicolumn{6}{|l|}{ Nabo } \\
\hline Ausência & $5,3^{\mathrm{ns}}$ & \multicolumn{2}{|c|}{-} & & \\
\hline Presença & 5,5 & \multicolumn{2}{|c|}{-} & & \\
\hline CV $(\%)$ & 11,1 & \multicolumn{2}{|c|}{10,1} & - & \\
\hline
\end{tabular}

${ }^{1 /} \mathrm{R}_{\mathrm{CMR}}=$ Redução do CMR. $\mathrm{R}_{\mathrm{CMR}}$ (cm por ramo) = CMR médio do cultivar na ausência de competição - CMR do cultivar sob competição; $\mathrm{R}_{\mathrm{CMR}}(\%)=\left(\mathrm{R}_{\mathrm{CMR}} / \mathrm{CMR}\right.$ médio do cultivar na ausência de competição) x 100. ${ }^{2} /$ Médias antecedidas pela mesma letra maiúscula nas linhas, entre condições de competição, ou seguidas pela mesma letra minúscula nas colunas, entre cultivares, não diferem pelo teste de Tukey a 5\% de probabilidade. ${ }^{\text {ns }}$ Valor do teste $\mathrm{F}$ da análise de variância não significativo a $5 \%$ de probabilidade.

O ciclo de crescimento dos cultivares não foi alterado pela competição de nabo (Tabela 3). Em geral, os cultivares mantiveram suas características de duração do ciclo, sendo os cultivares IAS 5 e BR 16 os mais precoces, e CEPS 9678, CEPS 9703 e FT 2000, os mais tardios. Em geral, as diferenças apresentadas confirmam a classificação genérica do ciclo de crescimento dos cultivares em precoces (CD 201, BR 16, IAS 5 e MSoy 6101), médios (Bragg, BRS 154 e Fundacep 38) e tardios (CEPS 9678, CEPS 9703, FT 2000 e RS 10).

A produtividade de grãos de soja foi reduzida pela competição de nabo nos cultivares BR 16, Bragg e CEPS 9678 (Tabela 4). O cultivar mais produtivo, nas duas condições de competição, foi o MSoy 6101. Já a menor produtividade de grãos na ausência de competição foi do cultivar CEPS 9703 e, na presença do nabo, do cultivar Bragg. A convivência da soja com Euphorbia heterophylla (leiteira) somente nos primeiros 45 dias do ciclo da cultura causa perdas de até $16 \%$ na produtividade de grãos de soja (Chemale \& Fleck, 1982). No presente trabalho, o nabo cresceu juntamente com os cultivares de soja apenas durante o período vegetativo (até $60 \mathrm{DAE}$ ), e perdas significativas em produtividade de grãos situaram-se entre 12 e $15 \%$. A queda de produtividade de grãos foi semelhante neste trabalho com nabo e naquele com leiteira, sugerindo que o nabo foi eficiente como simulador da competição de plantas daninhas dicotiledôneas durante o período vegetativo da soja.

Entre os cultivares mais produtivos, MSoy 6101 e CD 201 foram os que mantiveram a produtividade mais elevada em ambas as situações de competição, e também foram aqueles com uma das menores perdas de produtividade $(3 \%)$ decorrente da competição. Por outro lado, os cultivares BR 16, Bragg e CEPS 9678, pertencentes aos grupos de maturação precoce, médio e tardio, respectivamente, sofreram reduções significativas de produtividade (12 a $15 \%$ ) quando conviveram 
Tabela 3 - Produtividade biológica aparente ( $\mathrm{PB}$ - g por planta), índice de colheita aparente ( $\mathrm{IC}_{\mathrm{a}}-\%$ ) e ciclo de crescimento (dias após a emergência) de cultivares de soja, sob duas condições de competição com nabo. Fundacep, Cruz Alta-RS, 2000/01

\begin{tabular}{|c|c|c|c|}
\hline Fator/tratamento & $\mathrm{PB}_{\mathrm{a}}$ & $\mathrm{IC}_{\mathrm{a}}$ & Ciclo \\
\hline \multicolumn{4}{|l|}{ Cultivar } \\
\hline IAS 5 & $42,2 \mathrm{f}^{\frac{1}{}}$ & $43,4 \mathrm{bc}$ & $126,0 \mathrm{~g}$ \\
\hline BR 16 & $48,9 \mathrm{def}$ & $43,4 \mathrm{~b}$ & $128,2 \mathrm{~g}$ \\
\hline CD 201 & 49,1 ef & $46,7 \mathrm{~b}$ & $131,9 \mathrm{f}$ \\
\hline MSoy 6101 & 57,8 bcde & $46,9 \mathrm{~b}$ & $132,1 \mathrm{f}$ \\
\hline Bragg & $68,3 \mathrm{ab}$ & $41,7 \mathrm{c}$ & $140,1 \mathrm{de}$ \\
\hline BRS 154 & $65,3 \mathrm{ab}$ & $44,0 \mathrm{bc}$ & $139,9 \mathrm{e}$ \\
\hline Fundacep 38 & $60,1 \mathrm{bcd}$ & $46,7 \mathrm{~b}$ & $142,4 \mathrm{~cd}$ \\
\hline Fepagro RS 10 & 59,3 bcde & $43,2 \mathrm{bc}$ & $143,5 \mathrm{bc}$ \\
\hline CEPS 9703 & $61,4 \mathrm{abc}$ & $41,2 \mathrm{c}$ & $145,9 \mathrm{ab}$ \\
\hline FT 2000 & 52,6 cdef & $41,9 \mathrm{c}$ & $145,9 \mathrm{ab}$ \\
\hline CEPS 9678 & $71,7 \mathrm{a}$ & $51,7 \mathrm{a}$ & $146,9 \mathrm{a}$ \\
\hline CV $(\%)$ & 11,9 & 5,5 & 1,1 \\
\hline \multicolumn{4}{|l|}{ Nabo } \\
\hline Ausência & $59,4 \mathrm{a}$ & $43,9 \mathrm{~b}$ & $138,8^{\mathrm{ns}}$ \\
\hline Presença & $56,4 \mathrm{~b}$ & $45,9 \mathrm{a}$ & 138,0 \\
\hline CV $(\%)$ & 1,9 & 2,3 & 1,0 \\
\hline
\end{tabular}

1/ Médias antecedidas pela mesma letra letra minúscula nas colunas, entre cultivares ou condições de competição, não diferem pelo teste de Tukey a $5 \%$ de probabilidade. ${ }^{\text {ns }}$ Valor do teste $\mathrm{F}$ da análise de variância não significativo a $5 \%$ de probabilidade. com o nabo durante parte de seus ciclos. Enquanto a produtividade de grãos não se associou com a duração do ciclo de crescimento $(\mathrm{r}=0,09 ; \mathrm{p}=0,41)$, a redução de produtividade mostrou relação negativa com o ciclo quando determinado na presença de nabo $(\mathrm{r}=-0,41 ; \mathrm{p}=0,02)$. Mesmo que esse grau de associação não seja forte, quanto mais longo o ciclo de crescimento de plantas de soja, menor será a perda em produtividade de grãos. Nesse caso, essa resposta pode resultar do menor tempo de convivência do cultivar tardio de soja com o nabo, em relação ao precoce.

Em algumas pesquisas, cultivares tardios foram mais competitivos que os precoces (Monks \& Oliver, 1988; Shilling et al., 1995; Lamego et al., 2004; Nordby et al., 2007) e, em outras, foram os cultivares precoces os mais competitivos (Bennett \& Shaw, 2000; Jannink et al., 2000). Mesmo que nesta pesquisa com soja tenha se verificado associação entre o ciclo e a perda de produtividade de grãos em soja, a literatura é controversa a esse respeito. Essa divergência pode ser atribuída ao fato de que, dentro do grupo de cultivares estudados, aqueles de maturação tardia apresentam características de plantas que resultam em maior competitividade com plantas daninhas do que os precoces, ou vice-versa. As relações de competição, em geral, são definidas na fase

Tabela 4 - Produtividade de grãos $\left(\mathrm{kg} \mathrm{ha}^{-1}\right)$ de cultivares de soja, sob duas condições de competição com nabo. Fundacep, Cruz Alta-RS, 2000/01

\begin{tabular}{|c|c|c|c|c|}
\hline \multirow{2}{*}{ Cultivar } & \multirow{2}{*}{ Ausência de competição } & \multirow{2}{*}{ Presença de competição } & \multicolumn{2}{|c|}{$\mathrm{R}_{\mathrm{PROD}}{ }^{2 /}$} \\
\hline & & & $\left(\mathrm{kg} \mathrm{ha}^{-1}\right)$ & $(\%)$ \\
\hline IAS 5 & A $3122 \mathrm{~cd}^{1 /}$ & A $2997 \mathrm{~cd}$ & $155 \mathrm{abcd}$ & 5 \\
\hline BR 16 & A $3624 \mathrm{ab}$ & B $3129 \mathrm{bcd}$ & $495 \mathrm{a}$ & 14 \\
\hline CD 201 & A $3550 \mathrm{abc}$ & A $3491 \mathrm{ab}$ & $90 \mathrm{~cd}$ & 3 \\
\hline MSoy 6101 & A 3712 a & A 3656 a & $108 \mathrm{bcd}$ & 3 \\
\hline Bragg & A 3144 bcd & B $2664 \mathrm{~d}$ & $480 \mathrm{ab}$ & 15 \\
\hline BRS 154 & A 3426 abcd & A 3159 bc & $267 \mathrm{abcd}$ & 8 \\
\hline Fundacep 38 & A 3359 abcd & A 3225 abc & 214 abcd & 6 \\
\hline Fepagro RS 10 & A 3168 bcd & A $3100 \mathrm{bcd}$ & $106 \mathrm{bcd}$ & 3 \\
\hline CEPS 9703 & A 2956 d & A $3038 \mathrm{bcd}$ & $29 \mathrm{~d}$ & 1 \\
\hline FT 2000 & A 3366 abcd & A 3130 bcd & 235 abcd & 7 \\
\hline CEPS 9678 & A $3604 \mathrm{abc}$ & B 3168 abc & $436 \mathrm{abc}$ & 12 \\
\hline CV $(\%)$ Competição & \multicolumn{2}{|c|}{9,3} & - & \\
\hline CV $(\%)$ Cultivares & \multicolumn{2}{|c|}{6,4} & 64,9 & \\
\hline
\end{tabular}

1/ Médias antecedidas pela mesma letra maiúscula, comparadas nas linhas, entre condições de competição, ou seguidas pela mesma letra minúscula, comparadas nas colunas, entre cultivares ou condições de competição, não diferem pelo teste de Tukey a 5\% de probabilidade.

2/ Redução da produtividade de grãos: $\mathrm{R}_{\mathrm{PROD}}\left(\mathrm{kg} \mathrm{ha}^{-1}\right)=$ produtividade média do cultivar na ausência de competição - produtividade do cultivar em cada repetição na presença de competição; $\mathrm{R}_{\mathrm{PROD}}(\%)=\left(\mathrm{R}_{\mathrm{PROD}}\right.$ /produtividade média do cultivar na ausência de competição $) \times 100$. 
inicial de desenvolvimento da soja, sendo as plantas que possuem crescimento inicial mais vigoroso, em estatura ou em matéria seca, as mais competitivas com plantas daninhas. Esse comportamento independe da duração do ciclo de crescimento (Jannink et al., 2001).

A HC, quanto aos efeitos resultantes, pode ser desdobrada em supressão ou em tolerância (Goldberg \& Landa, 1991). Nesse enfoque, os cultivares CD 201, IAS 5 e RS 10 foram os que mais suprimiram a MPA e a produtividade de grãos de nabo (Fleck et al, 2006). Por outro lado, esses mesmos cultivares apresentaram as perdas na produtividade de grãos mais baixas, entre 2 e $5 \%$, em resposta à competição (Tabela 4). Estudos indicam que é possivel superar algumas barreiras que impedem a obtenção de cultivares competitivos e produtivos (Jannink et al., 2001) reunindo no mesmo cultivar ambas as características (Haefele et al., 2004). No presente trabalho, ocorreu associação positiva da produtividade de grãos de soja obtida na ausência de nabo com a verificada na presença do competidor $(r=0,37 ; p=0,01)$. Cultivares produtivos tanto na ausência como na presença de espécies daninhas devem ser priorizados em programas de melhoramento (Lemerle et al., 2001a). Incremento da produtividade de grãos, independentemente da competição com plantas daninhas, sugere adaptação local - atributo importante para obter cultivares detentores de elevada HC (Lemerle et al., 2001b).

Os cultivares CD 201, IAS 5, RS 10 e MSoy 6101 demonstraram HC superior à dos demais cultivares. CD 201 e MSoy 6101 mantiveram as maiores produtividades em ambas as condições de competição e, ainda, sofreram baixas perdas de produtividade devido à presença de nabo. Por sua vez, IAS 5 e RS 10, mesmo demonstrando HC promissora, apresentaram menor potencial produtivo. Apenas a baixa taxa de redução em produtividade de grãos foi equivalente entre os cultivares supracitados. No entanto, CD 201 e MSoy 6101 apresentam, em comum, alta produtividade quando submetidos à competição com nabo, mas estatura e CMR de suas plantas são divergentes: em geral, MSoy 6101 apresenta porte mais alto e ramos mais longos do que CD 201. Por outro lado, embora IAS 5 e RS 10 tenham suprimido de forma similar o nabo, suas plantas diferem em estatura, MPA e CMR (Fleck et al., 2006).

Diante das características frequentemente referidas na literatura e da aceitação do cultivar pelo agricultor, um genótipo com alta $\mathrm{HC}$ deve manter-se sob estresse competitivo, com elevada e rápida acumulação de matéria seca na fase inicial de crescimento, alta capacidade de ramificação, ramificação precoce, alocação preferencial de matéria seca para os ramos, estatura elevada, tolerância ao acamamento, baixa redução de produtividade sob estresse de competição e potencial de rendimento comparável aos cultivares existentes no mercado.

Verificou-se, neste trabalho, que os cultivares CD 201, MSoy 6101, RS 10 e IAS 5, em geral, divergem quanto às características estatura, NR e CMR de plantas, ciclo de crescimento e produtividade de grãos. Contudo, em comum, apresentam baixa perda de produtividade de grãos quando submetidos à competição com nabo e, no caso de CD 201 e MSoy 6101, detêm alto potencial de produtividade de grãos tanto na ausência como na presença de competição. Dificilmente uma única característica conferirá elevada $\mathrm{HC}$ às plantas de um cultivar (Lemerle et al., 1996), e sim a combinação de duas ou mais delas, que, necessariamente, não são as mesmas entre cultivares.

No Rio Grande do Sul, na última década, houve alteração na preferência por grupo de maturidade de cultivares de soja e em algumas práticas de manejo da cultura. A preferência pelo grupo de maturidade passou de 7 (ciclo médio), que na safra 1997/98 representou $40 \%$ da semente fiscalizada disponivel no RS (Reunião, 1998), para 6 (ciclo precoce) durante a fase de introdução e expansão do uso de cultivares resistentes ao glifosato. Atualmente, há forte tendência para cultivares do grupo 5 (superprecoce), devido principalmente a questões climáticas e de manejo de doenças. A indicação técnica para população de plantas passou de 40 plantas $\mathrm{m}^{-2}$ em 1998 (Reunião, 1998) para 30 plantas $\mathrm{m}^{-2}$ em 2006 (Reunião, 2006), e hoje em dia populações ainda menores (20 a 25 plantas $\mathrm{m}^{-2}$ ) são indicadas pelos obtentores para alguns cultivares. Ainda, por questões operacionais, produtores utilizam espaçamento entre fileiras de $50 \mathrm{~cm}$ ou mais 
e aumentam a proporção de área semeada mais cedo. Todas essas alterações no cultivo reduzem a HC da cultura com plantas daninhas e exigem selecionar cultivares que possam ter vantagem competitiva nessas condições sem depender de incremento no uso de herbicidas.

Os resultados deste estudo indicam que a resposta da soja à competição com nabo é variável entre os cultivares, caracterizando variabilidade genética que permite selecionar genótipos portadores de HC superior. A competição com nabo na fase vegetativa da soja reduz a estatura de planta, o comprimento médio dos ramos e a produtividade de grãos de soja. Entre os genótipos de soja utilizados, o cultivar MSoy 6101 destaca-se positivamente quanto à HC pela maior produtividade potencial de grãos na ausência de competição e pela capacidade de mantê-la diante da competição com nabo, sendo também o mais alto e com ramos mais longos sob competição.

\section{LITERATURA CITADA}

AARSSEN, L. W. Ecological combining ability and competitive combining ability in plants: toward a general evolutionary theory of coexistence in systems of competition. Am. Nat., v. 122, n. 6, p. 707-731, 1983

BENNETT, A. C.; SHAW, D. R. Effect of Glycine max cultivar and weed control on weed seed characteristics. Weed Sci., v. 48, n. 4, p. 431-435, 2000.

BIANCHI, M. A. et al. Partição da competição por recursos do solo e radiação solar entre cultivares de soja e genótipos concorrentes. Planta Daninha, v. 24, n. 4, p. 629-639, 2006.

BUHLER, D. D. Challenges and opportunities for integrated weed management. Weed Sci., v. 50, n.3, p. 273-280, 2002.

CALLAWAY, M. B. A compendium of crop varietal tolerance to weeds. Am. J. Alternative Agric., v. 7, n. 4, p. 169-180, 1992.

CHEMALE, V. M.; FLECK, N. G. Avaliação de cultivares de soja [Glycine max (L.) Merrill] em competição com Euphorbia heterophylla L. sob três densidades e dois períodos de ocorrência. Planta Daninha, v. 2, n. 1, p. 36-45, 1982.

CROTSER, M. P.; WITT, W. W.; SPOMER, L. A. Neutral density shading and far-red radiation influence black nightshade (Solanum nigrum) and eastern black nightshade (Solanum ptycanthum) growth. Weed Sci., v. 51, n.2, p. 208-213, 2003.
DREWS, S.; NEUHOFF, D.; KÖPKE, U. Weed suppression ability of three winter wheat varieties at different row spacing under organic farming conditions. Weed Res., v. 49, n. 5, p. 526-533, 2009.

FLECK, N. G. et al. Interferência de Raphanus sativus sobre cultivares de soja durante a fase vegetativa de

desenvolvimento da cultura. Planta Daninha, v. 24, n. 3, p. $425-434,2006$.

GAUDET, C. L.; KEDDY, P. A. A comparative approach to predicting competitive ability from plant traits. Nature, v. 334, p. 242-243, 1988.

GOLDBERG, D. E.; LANDA, K. Competitive effect and response: hierarchies and correlated traits in the early stages of competition. J. Ecol., v. 79, n. 4, p. 1013-1030, 1991

HAEFELE, S. M. et al. Field screening of diverse rice genotypes for weed competitiveness in irrigated lowland ecosystems. Field Crops Res., v. 88, n. 1, p. 39-56, 2004

JAMES, K. L.; BANKS, P. A.; KARNOK, K. J. Interference of soybean, Glycine max, cultivars with sicklepod, Cassia obtusifolia. Weed Technol., v. 2, n.4, p. 404-409, 1988.

JANNINK, J. L. et al. Index selection for weed suppressive ability in soybean. Crop Sci., v. 40, n.4, p. 1087-1094, 2000.

JANNINK, J. L.; JORDAN, N. R.; ORF, J. H. Feasibility of selection for high weed suppressive ability in soybean: Absence of tradeoffs between rapid initial growth and sustained later growth. Euphytica, v. 120, n. 2, p. 291-300, 2001.

JENNINGS, P. R.; AQUINO, R. C. Studies on competition in rice. 3 . The mecanism of competition among phenotypes. Evolution, v. 22, n.3, p. 529-542, 1968.

JORDAN, N. Prospects for weed control through crop interference. Ecol. Appl., v. 3, n. 1, p. 84-91, 1993.

LAMEGO, F. P. et al. Tolerância à interferência de plantas competidoras e habilidade de supressão por genótipos de soja - II. Resposta de variáveis de produtividade.

Planta Daninha, v. 22, n. 4, p. 491-498, 2004.

LEMERLE, D. et al. The potential for selecting wheat varieties strongly competitive against weeds. Weed Res., v. 36, n. 6, p. $505-513,1996$

LEMERLE, D. et al. Genetic improvement and agronomy for enhanced wheat competitiveness with weeds. Austr. J. Agric. Res., v. 52, n. 5, p. 527-548, 2001a.

LEMERLE, D.; VERBEEK, B.; ORCHARD, B. Ranking the ability of wheat varieties to compete with Lolium rigidum. Weed Res., v. 41, n. 3, p. 197-209, 2001 b. 
MONKS, D. W.; OLIVER, L. R. Interactions between soybean (Glycine max) cultivars and selected weeds. Weed Sci., v. 36, n.6, p. 770-774, 1988.

NORDBY, D. E.; ALDERKS, D. L.; NAFZIGER, E. D. Competitiveness with weeds of soybean cultivars with different maturity and canopy width characteristics. Weed Technol., v. 21, n. 4, p. 1082-1088, 2007.

PAYNTER, B. H.; HILLS, A. L. Barley and rigid ryegrass (Lolium rigidum) competition is influenced by crop cultivar and density. Weed Technol., v. 23, n. 1, p. 40-48, 2009.

RAJCAN, I.; SWANTON, C. J. Understanding maize-weed competition: resource competition, light quality and the whole plant. Field Crops Res., v. 71, n. 1, p. 139-150, 2001.
REUNIÃO DE PESQUISA DE SOJA DA REGIÃO SUL, 26., 1998, Cruz Alta. Indicações técnicas para a cultura da soja no Rio Grande do Sul e em Santa Catarina 1998/ 1999. Cruz Alta: UNICRUZ, 1998. 133 p

REUNIÃO DE PESQUISA DE SOJA DA REGIÃO SUL, 34., 2006, Pelotas. Indicações técnicas para a cultura da soja no Rio Grande do Sul e em Santa Catarina 2006/ 2007. Pelotas: Embrapa Clima Temperado, 2006. 240 p.

SHILLING, D. G. et al. Effect of soybean (Glycine max) cultivar, tillage and rye (Secale cereale) mulch on sicklepod (Cassia obtusifolia). Weed Technol., v. 9, n. 2, p. 339-342, 1995.

VOLL, E. et al. Competição relativa de espécies de plantas daninhas com dois cultivares de soja. Planta Daninha, v. 20, n. 1, p. $17-24,2002$ 